\title{
Characterization of the pscC (Type III secretion) gene of Pseudomonas aeruginosa (PA01) and assessment of immunogenicity of pscC protein in rats
}

\author{
Md Safiul Alam Bhuiyan ${ }^{1}$, Hafiza Sultana ${ }^{2}$, Kenneth Francis Rodrigues ${ }^{1 *}$, Fernandes Opook ${ }^{1}$ \\ ${ }^{1}$ Biotechnology Research Institute, University Malaysia Sabah, 88400 Kota Kinabalu, Sabah, Malaysia. \\ ${ }^{2}$ Rangpur Medical college, Rangpur, Bangladesh.
}

\begin{tabular}{|c|c|}
\hline ARTICLE INFO & ABSTRACT \\
\hline $\begin{array}{l}\text { Article history: } \\
\text { Received on: } 07 / 09 / 2016 \\
\text { Revised on: } 01 / 10 / 2016 \\
\text { Accepted on: } 21 / 11 / 2016 \\
\text { Available online: } 20 / 01 / 2017\end{array}$ & $\begin{array}{l}\text { Proteins associated with the bacterial membrane can be recruited for application as antigens for the development } \\
\text { of vaccines. This preliminary study was directed towards evaluating the antigenic properties of the Pseudomonas } \\
\text { aeruginosa (PA01) pscC protein which is a component of the Type III secretion system. Gene specific primers } \\
\text { were designed to isolate the pscC gene which was isolated, ligated onto the multiple cloning site of vector } \\
\text { pGS21(a), cloned and expressed in Escherichia coli (BL21). The molecular weight of the expressed pscC protein }\end{array}$ \\
\hline $\begin{array}{l}\text { Key words: } \\
\text { Pseudomonas aeruginosa, } \\
\text { pscC gene, type III secretion } \\
\text { system. }\end{array}$ & $\begin{array}{l}\text { was determined by SDS-PAGE (10\% sodium dodecyl sulphate-polyacrylamide gel electrophoresis) and was } \\
\text { found to be around } 57 \mathrm{KDa} \text { and purified by the size exclusion chromatography. Finally, the purified pscC protein } \\
\text { was injected subcutaneously into adult Sprague Dawley }{ }^{\circledR} \text { rats with a range of concentrations }(50,100 \text { and } 150 \mu \mathrm{g} \\
\text { per rat) respectively. Recombinant pscC antigen induced a specific humoral immune response against the antigen, } \\
\text { which was validated by Enzyme-linked immunosorbent assay (ELISA). The results concluded that anti-pscC } \\
\text { antibody was elicited in the animal model. }\end{array}$ \\
\hline
\end{tabular}

\section{INTRODUCTION}

Pseudomonas aeruginosa is a versatile Gram negative aerobic bacillus, found in a wide range of environmental habitats. This opportunistic pathogen causes both acute and chronic infections in patients with hospital-acquired pneumonia [1]. It has been classified as the fourth leading cause of nosocomial infection and is associated with cystic fibrosis; burn wound infection, and pneumonic septicaemia [2,3]. Due to recurrent causes of nosocomial infections Pseudomonas infections have become more complex and life-threatening infection, as standard treatments are becoming ultimately ineffective. This organism exhibits intense signs of antibiotic resistance to a wide variety of antimicrobial treatments, including Beta-lactams, Chloramphenicol and Fluoroquinolone [4]. Therefore, specific immune therapy is more desirable than conventional antibiotic therapy [5].

\section{* Corresponding Author}

Kenneth Francis Rodrigues, Associate ProfessorBiotechnology

Research InstituteUniversity Malaysia Sabah, Malaysia.

Email: kennethr@ums.edu.my
It is an urgent demand of time to implement therapeutic vaccination schemes against Pseudomonas infections. $P$. aeruginosa have its own type III secretion system (T3SS), with a protein translocation apparatus and the effector proteins which can be injected into host cells. The secretion and translocation stages comprise over 20 proteins gathered into a needle-like structure termed as injectisome [6]. The T3SS is the part of important virulence determinants of $P$. aeruginosa, in which the pscC protein is a fundamental part of the needle tip for $P$. aeruginosa (Fig 1). The pscC protein has been established to be an important protective antigen of the bacterium and regulate the secretion of translocator proteins to attach with host cell membranes. Once the bacterium interacts with host cell membranes, the T3SS system is activated and this in turn inhibits signal transduction resulting in cellular cytotoxicity or changes in the host immune responses. TheT3SS antigen may react with the host cell, whose maximum component should play a significant role in the host immunity. Therefore, immunization against T3SS antigen can prevent translocon association. However, the functional and regulatory information about this multimechanism of pscC antigen will facilitated for the design of novel recombinant vaccines as well as therapeutics. 
Effective vaccines are designed to stimulate the innate immune response as well as carry antigens to specific sub-cellular sites for the elicitation of antigen-specific cytotoxic $\mathrm{T}$ cells. Physical delivery to specific locations within a cell is one of the major challenges when developing a suitable candidate for T3SS antigen as a vaccine. Secretory needle antigens of T3SS are easily processed through T3SS pathways. These complexes form a host pathogen interaction is important to identify the molecular pathogenesis for developing an effective vaccine. As a result, the secretory T3SS antigen directly stimulates antigen-specific cytotoxic $\mathrm{T}$ cells through the delivery of antigens to the antigen presenting cells (APC), causing a humoral immune response [7, 8]. The proteins for transportation of T3SS pathway have distinct signals that direct them to the secretion machine to stimulate $\mathrm{T}$ helper cells, conferring protection to a diversity of infectious diseases [9].

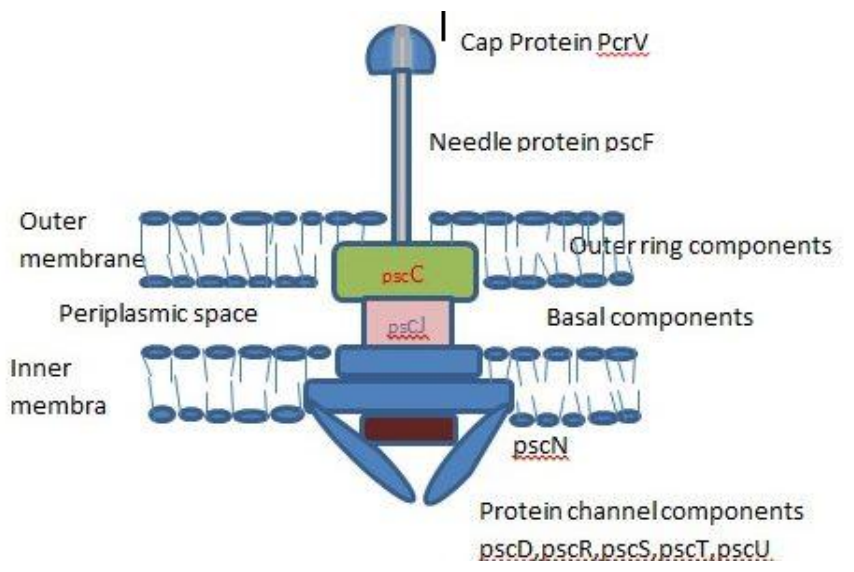

Fig. 1: Pseudomonas aeruginosa type III secretory needle apparatus. The type III secretory apparatus involves different types of protein mechanisms: Outer ring segment $(\mathrm{pscC})$, Cap component $(\mathrm{PcrV})$; needle component $(\mathrm{PscF})$; and basal components together with PscJ,PscD, PscR, PscS, PscT \& PscU (Sawa et $a l, 2014)$.

The preliminary aim of this study was to determine the immune response of the T3SS pscC antigen elicited in animal model. It has been suggested that recombinant or purified protein immunization may allow long-term persistence of immunogenic action in host cells without any risk of infection [10, 11]. Th1 and Th2 cells collectively responses on either Ag are in the secretory product (Th2) or an intracellular or membrane-anchored molecule [12]. These approaches are mostly reliant on the antigen presentation which has been capable to improve immune stimulation to recombinant vaccines. Clinical trials have attested to the safety, efficiency and efficacy, as well as wide application of this immunization technique [13]. The cell surface display of a heterologous antigenic determinant is advantageous for the induction of an antibody against a specific antigen. The orientation of target antigens has been used to develop recombinant vaccines for immunization on rats for the capture and detection of an antibody from serum [14]. The recombinant version of the pscC needle protein of $P$. aeruginosa can be used as a specific antigen for indirect ELISA to screen the antibodies generated against specific protein in response to immunization of the rats.

\section{MATERIALS AND METHODS}

\subsection{Growth of $P$. aeruginosa (PA01) and Isolation of Bacterial DNA}

The $P$. aeruginosa PA01 culture was obtained from the ATCC. Cultures of PA01 were grown in autoclaved LB (LuriaBertani) broth and agar containing peptone $(10 \mathrm{~g} / \mathrm{L})$, Yeast extract $(5 \mathrm{~g} / \mathrm{L}), \mathrm{NaCl}(10 \mathrm{~g} / \mathrm{L})$ and agar $(15 \mathrm{~g} / \mathrm{L})$. Bacterial DNA isolation was performed via following Aljanabi and Martinez method which was used for rapid salt extraction of high quality genomic DNA for PCR base technique [15]. The plasmid vectors pGS-21a (Gene script, New Jersey) was used as vector for cloning and expression. The complete Freund's adjuvant (Sigma, USA) was used as an adjuvant for delivery of protein in rats. LB media containing $100 \mu \mathrm{g} / \mathrm{ml}$ of ampicillin were used to grow E.coli clones at $37^{\circ} \mathrm{C}$.

\subsection{Development of gene constructs for expression of recombinant pscC gene}

PCR amplification of pscC gene $(1.46 \mathrm{~kb})$ of $P$. aeruginosa was performed using specific primers. Primers were designed according to the $\mathrm{pscC}$ gene sequence which was retrieved from the NCBI GenBank (NP_250407). Then nucleotides were selected from both 5' and 3' ends of the pscC gene and restriction sites for EcoRI and HindIII were introduced at the 5' and 3' ends respectively in order to facilitate cloning. The forward primer: TCAgaattcCCAGCCTGCCTTACGACTAT, with the restriction site for EcoRI, and Reverse primer: CGC-ccatggCAACTCGTCGATTTCAAGCA, with the restriction site for HindIII. Amplification of the gene was performed $20 \mu \mathrm{l}$ of total volume containing $2 \mu \mathrm{l}$ DNA as a template, $4 \mu \mathrm{l}$ of $5 \times \mathrm{PCR}$ buffer (Promega), $1.2 \mu \mathrm{l} 1.5 \mathrm{Mm} \mathrm{Mgcl}_{2}$ (Promega), $0.2 \mu \mathrm{l}$ of $10 \mathrm{Mm}$ dNTPs (Promega), $0.2 \mu \mathrm{l}$ of tag polymerase (Fermentas, USA), 2 $\mu \mathrm{l}$ of primer (1st BASE Laboratories, Malaysia) oligonucleotides (Forward and Reverse), and $10.4 \mu \mathrm{l}$ sterilizes distilled water.

The amplification was performed in a thermal cycle program for initial denaturation at $96^{\circ} \mathrm{C}$ for $3 \mathrm{~min}, 30$ cycles of 20 $\mathrm{Sec}$ at $94^{\circ} \mathrm{C}, 40 \mathrm{Sec}$ at $56^{\circ} \mathrm{C}$ and $2 \mathrm{~min}$ at $72^{\circ} \mathrm{C}$. After final extension of $10 \mathrm{~min}$ at $72^{\circ} \mathrm{C}$, the sample was cool to $4^{\circ} \mathrm{C}$. The presence and yield of specific PCR products of approximately 1,500 base-pair was confirmed by gel electrophoresis in $1 \%$ agarose gel. DNA samples were loaded in wells and the electrophoresis was carried out at 100 volts. Then the DNA bands were visualized under ultraviolet (UV) trans-illuminator.

\subsection{Cloning and expression of pscC gene}

The PCR products were purified using the gel purification kit according to the manufacturer's instructions (Fermentas, USA). The purified PCR product was cloned into the pGS-21a vector containing $\mathrm{T} 7$ promoter to induce the expression of the cloned gene and selected EcoRI and HindIII were the appropriate restriction sites on pGS-21a vector. Plasmid pGS-21a 
and pscC gene (PCR products) were further double digested with EcoRI and HindIII (New England Biolabs, Inc, Beverly, MA). The PCR product of the $\mathrm{pscC}$ gene was ligated into the vector using T4 DNA ligase (Fermentas, USA) according to the manufacturer's instructions. The ligation product was used to transform into $E$. coli of Top 10 competent cells by $\mathrm{CaCl}_{2}$ method [16]. The insert plasmids were identified by colony PCR. The inserted sequence and its reading frame were confirmed by EcoRI and HindIII digestion and DNA sequence analysis. The generated pGS-pscC inserted plasmid was again sub-cloned into competent expression cells of $E$. coli BL21 (DE3) following same method described as cloned of Top10 competent cells.

The transformant cells were inoculated into the LB containing ampicillin in test tubes and incubated at $37^{\circ} \mathrm{C}$ for 16 hours with continuous stirring $(200 \mathrm{xg})$ until the optical cell density reached 0.4-0.6 at $\mathrm{OD}_{600}$. Subsequently, the culture was induced with $0.5 \mathrm{mM}$ IPTG and maintained at $37^{\circ} \mathrm{C}$ on a rotary shaker set at $200 \mathrm{xg}$.

The un-induced sample $(1 \mathrm{ml})$ was withdrawn prior to induction for used as a control. Afterwards, induced sample was taken hourly and last sample was picked after 16 hours of induction to observe the time course study of the expression. The soluble and insoluble fractions were obtained by treating the pellet with 1ml of PBS (Phosphate Buffer Saline) and lysed using ultra sonication on ice. The insoluble fractions of the protein were run in the 10\% SDS-PAGE gel using coomassie Brilliant blue with protein marker (Bio-5150, 1st BASE). After extraction of the intense protein gel, the identification of protein by mass spectrometry was performed. Peptides were extracted according to the Brangan's methods followed by digestion with trypsin which was analyzed using MALDITOF-TOF mass spectrometer with proteomics Analyzer (48000) [17]. Spectra were analyzed to identify the protein of interest by Mascot sequence matching software with Ludwig NR Database.

\subsection{Purification and Immunization of pscC protein in rats}

The soluble fraction of pscC protein was purified by using by Size exclusion chromatography (SEC). The SEC system (Akta Prime) was calibrated according to the supplier's instruction. S-100HR column (GE Healthcare) attached to the Akta Prime System was equilibrated using $0.05 \mathrm{M}$ Sodium Phosphate, $0.15 \mathrm{M} \mathrm{NaCl}, \mathrm{pH} 7.2$ at a flow rate of $2.6 \mathrm{ml} / \mathrm{min}$. The possible fractions were generated through the significant peaks and collected the specific column for desired protein by chloroform/methanol precipitation method. The fractions were further analysed using 10\% SDS-PAGE with Pre-staining Protein Marker.

The male adult Sprague-Dawley Rats (4-8 weeks old) weighing 150-200gms were obtained from Tes Jaya laboratory services, Pulau Pinang, Malaysia. All these animals were acclimatized and quarantined before commencement of the experiment. This study had approval from the Animal Care and Use Committee and Institutional Biosafety Committee (IACUC), Malaysia prior setup the experimental design. Animals were reared in plastic cages using paddy husk bedding at room temperature ( 25 $\left.\pm 1^{\circ} \mathrm{C}\right)$ and humidity $(50 \pm 5 \%)$ in ABSL-3. For evaluation of the immunogenicity of $\mathrm{pscC}$ protein, soluble protein was administrated in rats with various doses [Low $(50 \mu \mathrm{g})$, medium $(100 \mu \mathrm{g})$ and high $(150 \mu \mathrm{g})]$. Rats were randomly assigned to four groups composed of 6 animals in each. Standard restraints were used during the injection.

Group 1 received $100 \mu 10.1 \mathrm{M}$ phosphate buffered saline (PBS) with equal of complete Freund's adjuvant (Sigma, USA) via the subcutaneous route as a control. The Group 2 immunized with $50 \mu \mathrm{g}$ of total soluble protein mixed with the same volume of complete Freund's adjuvant. The group 3 and 4 were injected following the same technique with the equivalent of same adjuvant which was treated with $100 \mu \mathrm{g}$ (medium) and $150 \mu \mathrm{g}$ (High). Rats of all groups were immunized on days 0 and 14 and the immunized sera were collected on days $7,14,21,28$ and 35 respectively.

Retro-orbital bleeding was done for blood collection and blood samples were collected under general anaesthesia $(95 \%$ Diethyl ether with enclosed induction chamber). Serum samples from immunized and control rats were centrifuged at $11,600 \mathrm{xg}$, and stored at $-80^{\circ} \mathrm{C}$. The collected sera were subjected to enzymelinked immunosorbent assay (ELISA) assay for the determination of the level of antibodies in sera.

\subsection{Enzyme-linked immune-sorbent assay (ELISA)}

Each sample was screened by indirect ELISA for specific immunoglobulin $\operatorname{IgG}+\operatorname{Ig} \mathrm{A}(\mathrm{H}+\mathrm{L}$ chain specific) using goat anti rat-antibody (Southern Biotech, USA). The recombinant antigen was mixed and poured into the 96-well Polystyrene micro-titre (Membrane solution, USA) plates. After coating the antigenic samples, the micro plates were covered and incubated on a shaker at $4^{\circ} \mathrm{C}$ for 16 hours which was washed three times with $100 \mu \mathrm{l}$ $0.05 \%$ (V/V) Tween 20 in PBS, blocked by adding $150 \mu 1$ of PBS $-3 \%(\mathrm{~W} / \mathrm{V})$ BSA followed by incubation for $90 \mathrm{~min}$ at room temperature. Control and test sera were diluted 1:100 in the blocking agent of PBS-A- $0.5 \%$ to which $0.05 \%$ of Tween 20 was added. Further, after the serial dilution of serum samples at 1:300, $1: 600 \& 1: 900$ they were loaded to the micro plate separately and incubated. The plates were washed and applied on goat anti-rat $\operatorname{IgM}+\operatorname{IgG}$ antibodies followed by incubation and another wash step. $100 \mu \mathrm{l}$ of conjugated alkaline phosphatase secondary Abs in PBS-1\% and BSA (1/1000) was added to the wells and incubated at room temperature followed by the wash step. P-Nitro phenyl phosphate (Southern Biotech, Birmingham) substrate tablet (5mg/tablet) was dissolved in DSB (1tablet/15ml of DSB) buffer. Subsequently, $100 \mu$ l of substrate solution was mixed to all tests well and kept at room temperature for $15 \mathrm{~min}$ until a yellow colour developed.

The optical density (OD) was measured using an ELISA plate reader (Infinite ${ }^{\circledR}$ M-200 PRO, TECAN). The OD results of all samples were calculated as percentage of positive control by using the OD value of the positive control serum by deducting the average $O D$ value of blank serum. 


\section{RESULTS AND DISCUSSION}

\subsection{Plasmid DNA constructions}

PCR amplified product was run on a $1 \%$ agarose gel and desired band for the respective target pscC gene was found without any primer and dimer. The PCR fragments were found to be approximately $1.46 \mathrm{~kb}$ (Figure 2A) amplified from the genomic DNA.

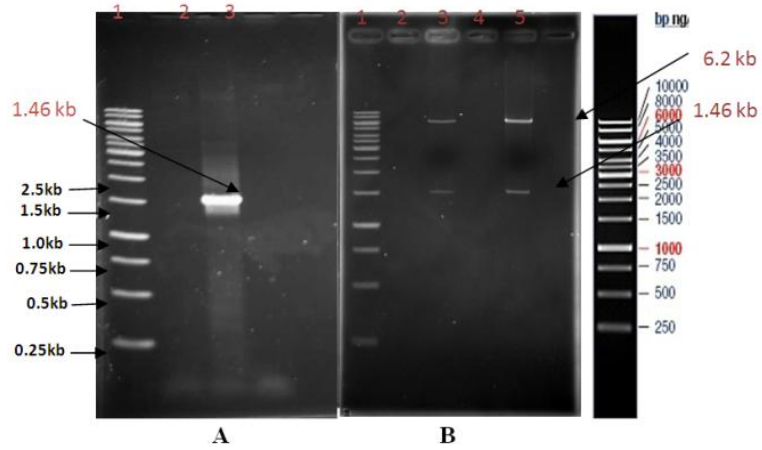

Fig. 2: The pscC gene was amplified with the specific designed primers from Pseudomonas aeruginosa PA01 strain. Figure (A), Lane 1: Hyper ladder $1 \mathrm{~kb}$ gene ruler DNA Ladder (SM 0314, Thermo Scientific). Lane: 2 Control (buffers and reagent without genomic DNA) Lane 3: pscC PCR product approx. $1.46 \mathrm{~kb}$. The figure (B), Recombinant plasmid (pGS21-psc) along with Lane 1: $1 \mathrm{~kb}$ DNA ladder; Lane 3 \& 5: the digested pGS-21a plasmid with EcoRI and HindIII. The gel was prepared by $1 \%$ Agarose in TBE buffer and run at 100 volts for 1 hour.

After confirmation, the PCR products were excised out of the agarose gel and purified using a gel extraction kit and digested with restricted enzyme for conformation which was represented in Figure 2B. The synthesized PCR product was then ready for cloning into pGS-21a plasmid vector. The pGS-21a plasmid was constructed by PCR amplification of the coding region of pscC with EcoRI and HindIII sites and ligating the pGS21a vector cut with the same enzymes. To determine whether the pscC fragment was successfully ligated in the pGS-21a plasmid, which were then digested with the EcoRI and HindIII to release the expected size of pscC gene. After $1 \%$ agarose gel examination, the RE mixture exposed the presence of two bands. The upper band was consistent to linear according to plasmid size (Approximately $6.2 \mathrm{~kb}$ ) and another band was corresponding to the expected molecular size of pscC gene around $1.46 \mathrm{~kb}$.

\subsection{Cloning and expression of pscC gene in $E$. coli}

The pGS-21a plasmid was transferred to E. coli TOP10 and BL21 (D3) and confirmed respectively by restriction digestion, colony PCR and sequencing. The clones were subjected to colony PCR and an amplified $1.46 \mathrm{~kb}$ band was obtained as that of positive control. The plasmid showed the presence of $1 \mathrm{~kb}$ insert and clones were confirmed through PCR and restriction analysis in Figure 3. The PCR positive recombinant clones were also subjected to restriction digestion using EcoRI and HindIII. The presence of about $1.46 \mathrm{~kb}$ insert was confirmed by electrophoresis and the positive clone was sequenced with $\mathrm{T} 7$ promoter primer (Forward and Reverse). Later than confirmation, clones were further subjected to plasmid extraction, followed by RE and plasmid sequence analysis.

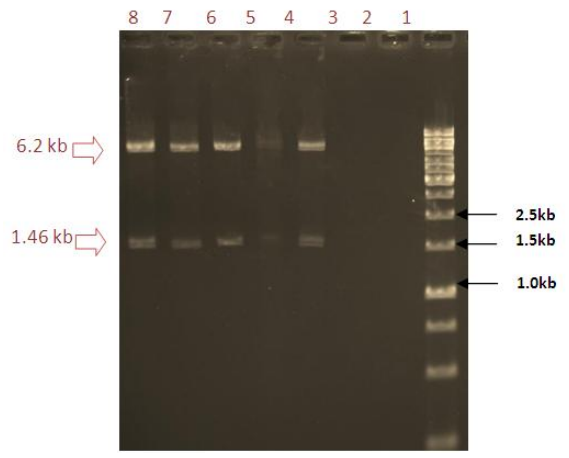

Fig. 3: Gel electrophoresis of positive colonies after transformation of target genes in $E$. coli TOP10 by colony PCR and restriction digestion of recombinant plasmid along with RE. The figure was indicated that 5 positive (Lane: $4,5,6$, $7, \& 8$ ) insert colonies with control (Lane: 2 \&3).The digested pGS-21a plasmid with EcoRI and HindIII presented the $1.46 \mathrm{~kb}$ of target pscC gene along with $6.2 \mathrm{~kb}$ vector (Lane: 4-8) and control (Lane: 2 \& 3). Gel was prepared using $1 \%$ agarose in TBE buffer and run at 100 volts for 1 hour.

The sequences were then analyzed via BLAST, compared with the reference sequences formerly deposited in NCBI. The sequences was compared to the NCBI database which was revealed about $97 \%$ similarity compared the sequences of pscC in BLASTn algorithm. As of the colony PCR the pGS-21a with inserted pscC gene was found approximately $1.46 \mathrm{~kb}$ size and control showed the $1.0 \mathrm{~kb}$. Therefore, it can be concluded that the recombinant plasmid carried the targeted pscC gene.

The protein expression was observed in host strains of E.coli BL21 (D3) cells and the most prominent band was appeared at $\sim 84 \mathrm{kDa}$ in 4 samples which was illustrated in Figure 4.

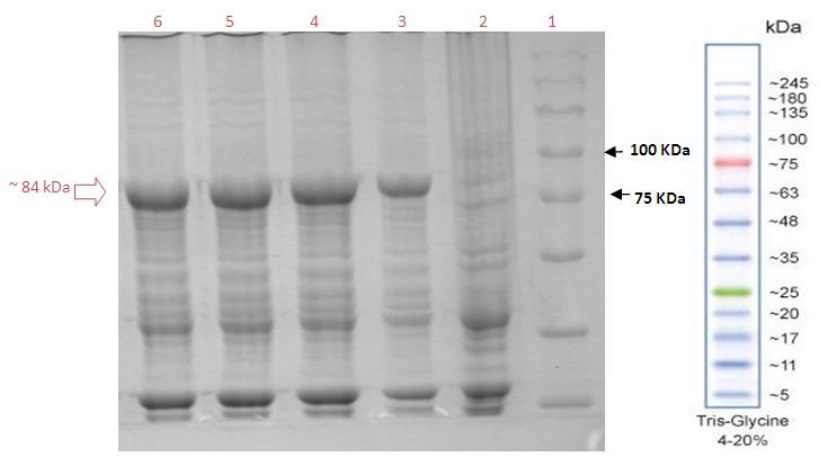

Fig. 4: SDS-PAGE analysis of the supernatant fraction of the small scale production of pscC in E. coli at $37^{\circ} \mathrm{C}$. Following Cells harbouring pGS-21a were harvested, the supernatant fractions were run on a $10 \%$ SDS-PAGE, 150 $\mathrm{V}$ for $1 \mathrm{hr} 30 \mathrm{~min}$ and stained with Coomassie Brilliant Blue. The numbers at the top indicate lanes and the molecular weights of the standards are indicated in the left margins. Lane 1: Protein ladder, Lane 2: Negative control without IPTG (No band), Lane $3 \&$ 6: positive control with IPTG followed with clear bands $(\sim 84 \mathrm{kDa})$

The soluble and insoluble fractions were obtained by resuspending the cell pellet in buffer and sonicated on ice. The slightly visible soluble band for scarce was detected in supernatant phase after visualized under SDS-PAGE (Figure 5). Consequently, a prominent band of the target protein $\mathrm{pscC}$ appeared which was 
visually distinguishable from other proteins based the un-induced controls. Recombinant $E$. coli also showed a distinct band with an approximate cumulative size of $\sim 57 \mathrm{kDa}$ with His tag (6XHis) and GST Tag at the size of $1 \mathrm{kDa}$ and $26 \mathrm{kDa}$ respectively. For further substantiation, the protein samples were digested by trypsin and peptides were extracted by MALDITOF-TOF mass spectrometer. Spectra were analyzed to identify the protein of interest using Mascot sequence matching software. The result indicated that the amino sequence of pscC protein specified a high ionic scoring match and similar with two peptide sequences appeared in the same protein. The protein identity and mass match were statistically more significant. Protein was analysed and noticed the one matched peptide to the same pscC protein, which was higher confidence for correct protein identified in Figure 6.

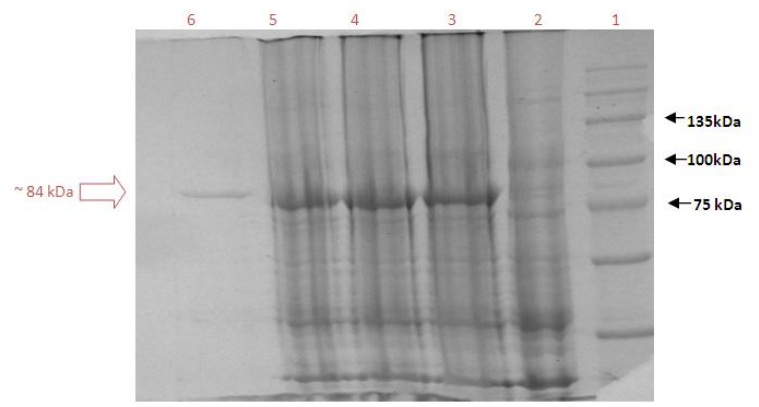

Fig. 5: Solubility of pscC expression in E. coli was harvested after IPTG induction for representing the pellet fraction (Insoluble protein) and the supernatant fraction (Soluble). Proteins were analysed on a 10\% SDS-PAGE. The molecular weights of the standards are indicated at the right margins. Lane 1: Protein ladder, Lane 2: without IPTG induction (control), Lane 3 - 5: showed in insoluble pscC bands and Lane 5 indicated the soluble band ( $84 \mathrm{kDa})$.

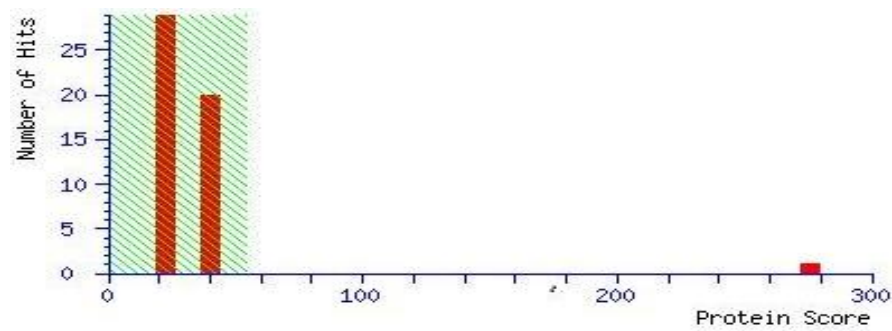

Fig: 6: Protein Identification by MS (Mass spectrometry). The result indicated that the amino acid sequence of $\mathrm{pscC}$ protein specified a high ionic scoring match and similar two peptide sequences appeared in the same protein. The protein identity and mass match were statistically more significant.

Source: https://sysbio-mascot.wehi.edu.au/mascot

\subsection{Purification and Immunization of pscC protein in rats}

The crude fraction was further purified and subjected to gel filtration on a Superdex followed by purification analysis using SDS-PAGE. The chromatogram showed a mixture of monomer and dimer state. The distinct peak was observed in 40 to 47 fractions and the small picks were noticed in 22 to 41 fractions. Additional stage was precipitating the fractions followed by the protocol of Wessel and Flugge [18]. The precipitated proteins were run once again in SDS-PAGE and protein in the lane of fraction 27, 28, 29 columns presented the correct band as their predicted molecular weight of approximately $\sim 84 \mathrm{kDa}$ in Figure 7 . After immunization, the antibody levels were measured by indirect
ELISA. The result showed that the rat antibody demonstrated a positive value against the immunized $\mathrm{pscC}$ antigen. As shown in the graphical representation in figure 8 , the level of immunoglobulin measured over the 0 to 5 th week for all the immunized rats. The $\mathrm{OD}_{405}$ Values for different weeks of serum from the post immunized blood were represented in Table 1. The 4 th and 5th weeks of all groups of immunized sera were shown in positive value.

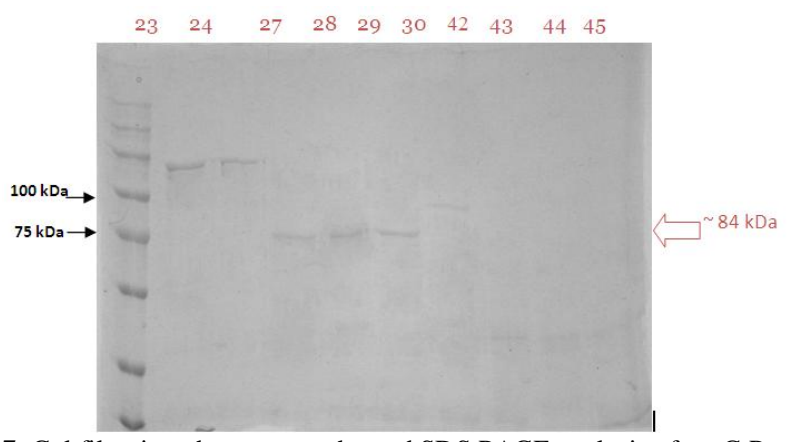

Fig. 7: Gel filtration chromatography and SDS PAGE analysis of pscC Protein; initial peaks showed a protein band of $\sim 84 \mathrm{kDa}$ in column of 27,28 and 29 correspondingly.

Table 1: $\mathrm{OD}^{405}$ Values for different weeks of serum from post immunization.

\begin{tabular}{ccccccc}
\hline Dose & 1 wk & 2 wks & 3 wks & 4 wks & 5 wks & Dilution \\
\hline \multirow{3}{*}{ Low Dose } & 0.0776 & 0.1492 & 0.1925 & 0.9165 & 1.0864 & $1 / 100$ \\
& 0.0734 & 0.0448 & 0.1756 & 0.5618 & 0.8027 & $1 / 300$ \\
& 0.0344 & 0.0509 & 0.2648 & 0.3541 & 0.5138 & $1 / 600$ \\
\hline \multirow{3}{*}{ Medium Dose } & 0.1124 & 0.1379 & 0.312 & 0.9105 & 1.3514 & $1 / 100$ \\
& 0.0168 & 0.0662 & 0.3034 & 0.643 & 1.041 & $1 / 300$ \\
& 0.0174 & 0.048 & 0.3167 & 0.4225 & 0.7889 & $1 / 600$ \\
\hline \multirow{3}{*}{ High Dose } & 0.1455 & 0.3252 & 0.2734 & 1.0155 & 1.3434 & $1 / 100$ \\
& 0.053 & 0.2857 & 0.3406 & 0.6363 & 1.2218 & $1 / 300$ \\
& 0.0402 & 0.0678 & 0.2536 & 0.3926 & 0.8464 & $1 / 600$ \\
\hline \multirow{3}{*}{ ontrol } & 0.0731 & 0.0841 & 0.0582 & 0.5634 & 0.0855 & $1 / 100$ \\
& 0.0657 & 0.0649 & 0.0588 & 0.0825 & 0.0287 & $1 / 300$ \\
& 0.0648 & 0.0546 & 0.0318 & 0.0438 & 0.0098 & $1 / 600$ \\
\hline
\end{tabular}

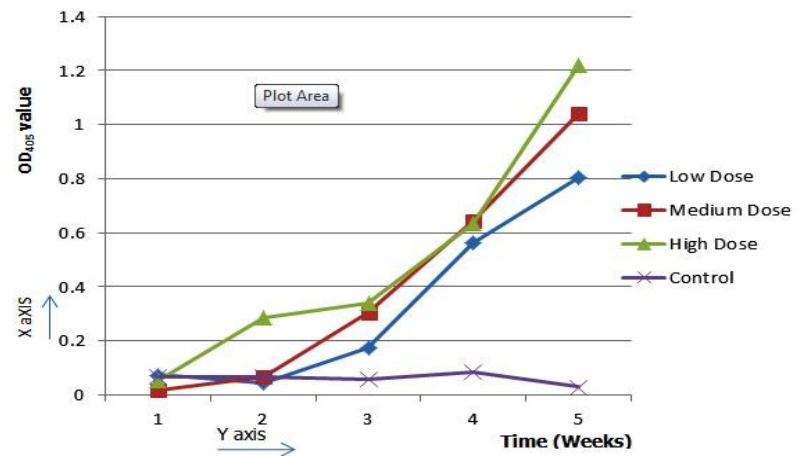

Fig. 8: Serum antibody was measured by indirect ELISA and antibody level responds of immunized rat Sera which collected on 7, 14, 21, 28, 35 days. Rats were immunized $(\mathrm{S} / \mathrm{C})$ with $50 \mu \mathrm{g}, 100 \mu \mathrm{g}$ and $150 \mu \mathrm{g}$ of $\mathrm{pscC}$ protein respectively. No immunization was found in the control group $(50 \mu \mathrm{g}$ of PBS with equivalent adjuvant). The figure represents the serum antibody levels at 1:300 dilutions against pscC surface coat antigen.

Four weeks after immunization, The $\mathrm{OD}_{405}$ values at $1: 300$ dilutions were $0.56,0.64$ and 0.63 for the low, medium and high dose respectively. Similarly, at the 5 weeks the antibody level was further increased and the $\mathrm{OD}_{405}$ value at 1:300 dilutions to $0.80,1.04$ and 1.22 for the low, medium and high dose 
respectively. Though for the titer measurement, a standard was needed since we do not have. The OD value was compared with unimmunized and immunized serum in rodent model. It was found that immunized OD value was 2 to 3 folds higher than the control OD value after 3 weeks. The result illustrated that the rat antibody demonstrated a positive value against the immunized serum based on OD value. The levels of the humoral immune responses showed higher antibody of Ag-specific serum immunoglobulin compared to with the controls group. The control groups were always (Group-1) negative to the $\mathrm{pscC}$ antigen throughout the study. The humoral immune responses were detected in all protein immunized groups and continued increasing after 4th weeks of immunization as indicated by the antibody level. The increased antibody was presented the dose dependant until the 5th weeks. It was noted that the medium dose $(100 \mu \mathrm{g})$ and higher dose $(150 \mu \mathrm{g})$ of protein antigen elicited a stronger immune response as compared to the lower dose $(50 \mu \mathrm{g})$. $P$. aeruginosa is a major cause of most opportunistic and nosocomial infections. Although conventional antibiotics are more resistance to Pseudomonas organism, now it is challenging to find an alternative immunize therapy. In these circumstances, a monoclonal antibody-based approach is still exploration for the inhibition of Pseudomonas infection [19]. Monoclonal antibodies have been established to improve of bacterial permission, stop the colonization and invasion, and avoid the destruction which is triggered by cytotoxic influences [20]. During the past few years, recombinant protein vaccines have shown the highest innovation in modern medical technology. Immunization with microbial antigen has delivered the protective immunity in animal models and considered a potential useful vaccine strategy [21]. Based on previous findings, there are various kinds of immunization have been observed against Pseudomonas infection such as killed vaccine [22], purified outer membrane subunit vaccine [23], plasmid immunization [24] and synthetic peptide immunization [25]. The immune response in a mouse animal model to consecutive recombinant protein base vaccine could able to neutralizing the bacterial virulent toxin [26]. It is supported that the use of genetic immunization technique in which a random assortment of genes from a bacteria's genome to practice for immunization purposes [27]. So, it is supposed to be clear that immunization is the best way of protection against outer membrane secretin antigen of T3SS. A previous study described about the immunogenicity of Pseudomonas cap segment (PcrV) of T3SS needle protein. The anti-PcrV monoclonal antibodies were detected after recombinant PcrV protein was used to immunize in a mouse model. The subgroup of anti-PcrV antibody can repressed T3SS function which was observed in cell lysis assay and designed for assessment of protective activity in a $P$. aeruginosa mouse acute pneumonia [28]. Protection or defence in animal models gives only the recommendation of the potential efficiency of that vaccine in humans [29]. Recently, Mingzi et al., 2014 have published the immunogenicity of pcrV gene (T3SS) encoding needle protein was immunized on mice and evaluated the efficiency of vaccines in Pseudomonas encoding single antigen
[30]. The results revealed that mammalian expression vector with the pcrV gene could elicit a sufficient level of specific antigen to induce the humoral antibody. Based on Brain et al., 2001 study, outer membrane of oprF gene of $P$. aeruginosa was immunized by plasmid that indicated that the efficacy of this vaccine can be able to elicited anti-oprF that confers protection of rodents against chronic pulmonary infection. Moreover, the results are similar to previous published results producing defence mechanism in rodent models by immunization with purified outer membrane protein from $P$. aeruginosa [31]. The fact is, without testing its effectiveness in animal models, the recombinant antigen has not yet been applied to induce in the human body for assessment of their efficacy and level of immune responses. It is necessary to conduct a challenging experiment in which live Pseudomonas can be injected into immune animals to examine the viability of rat and colony contents of Pseudomonas spp. Our further expectation, we tried to determine an applicable vaccine against Pseudomonas for clinical trial. Clinical challenge is essential for recombinant antigen efficacy in animal models for assessing their efficacy and level of immune responses. It was also not clear yet, what about the optimal vaccine modalities to induce potent neutralizing antibody responses or to strong humoral immune respond ensures capable to destroy against the infected cell. It is factual that, the recombinant protein vaccine, which is able to induce protection from Pseudomonas infection, might be more realistic for ending global. In précis, it is an appropriate challenging strategy for exploration of surface T3SS pscC antigen, which has been characterized from PAO1 genome as a vaccine candidate. The pscC gene $(1.46 \mathrm{~kb})$ encodes a $57-\mathrm{kDa}$ immunogenic outer membrane associated protein of PA01 strain. The protein was characterized in SDS-PAGE and purified from E. coli as a fusion protein to identify anti-pscC specific antibodies in the serum of Sparagury rat. Therefore, it is posited that recombinant $\mathrm{pscC}$ protein is capable of becoming a strong carrier and processor for the presentation of target foreign peptides in MHC II to stimulate the $\mathrm{T}$ helper cell based humoral immune system in a host cell. The expectations for treatment and prevention of human disease by immunization are changing and the recurrent refinement of these abilities signify a fit for the current as well as the future manufacture of a vaccine platform against Pseudomonas infection.

\section{CONCLUSION}

This study provides preliminary experimental evidence indicating that the outer membrane protein $\mathrm{pscC}$ can serve as an elicitor of the humoral immune response in rats. We recommend that future studies focus on a larger sample size and explore a range of open reading frames to determine the precise location of the antigenic component of the $\mathrm{pscC}$ protein.

\section{BIOSAFETY AND ANIMAL ETHICS}

The study was approved by the Biotechnology Research Institute Institutional Biosafety Committee (BRIBC). The animal study was carried out in the Level 3 Biological Containment 
Facility (ABSL-3) at the Biotechnology Research Institute, University Malaysia Sabah. Recombinant protein expression procedures were carried out using Escherichia coli (BL21) which is classified as a (B) strain that is exempted under the Malaysian Biosafety Law.

\section{Financial support and sponsorship: Nil.}

Conflict of Interests: There are no conflicts of interest.

\section{REFERENCES}

1. Driscoll JA, Brody SL, Kollef MH. The epidemiology, pathogenesis, and treatment of Pseudomonas aeruginosa infections. Drugs. 2007; 67: 351368.

2. Daniels C, Griffiths C, Cowles B, Lam J. Pseudomonas aeruginosa Oantigen chain length is determined before ligation to lipid a core. Environmental Microbiology. 2002; 4: 883-897.

3. Bernhardt TG, Wang IN, Struck DK, Young R. Breaking free: "protein antibiotics" and phage lysis. Research Journal of Microbiology. 2002; 153: 493-501.

4. Zhang, L, Li XZ, Poole K. Fluoroquinolone susceptibilities of effluxmediated multidrug resistant Pseudomonas aeruginosa, Stenotrophmonas maltophila and Burkholderia cepacia. Journal of Antimicrobial Chemotherapy. 2001; 48: 549-552.

5. Cryz, SJ Jr, Pitt TL, Furer E, Germanier R. Role of lipopolysaccharide in virulence of Pseudomonas aeruginosa. Infection and Immunity. 1984; 44: 508-513

6. Ruano-Gallego D, Álvarez B, Fernández LÁ. Engineering the Controlled Assembly of Filamentous Injectisomes in E. coli K-12 for Protein Translocation into Mammalian Cells. ACS synthetic biology. 2015; 4:1030-1041.

7. Amanna I, Slifka M. Contributions of humoral and cellular immunity to vaccine-induced protection in humans. Journal of Virology. 2011; 411: 206-215.

8. Chen LM, Briones G, Donis RO, Galan JE. Optimization of the delivery of heterologous proteins by the Salmonella enterica serovar Typhimurium type III secretion system for vaccine development. Infection and Immunity. 2006; 74: 5826-5833.

9. Galan JE, Wolf-Watz H. Protein delivery into eukaryotic cells by type III secretion machines. Nature. 2006; 444: 567-573

10. Perez O, Batista-Duharte A, Gonzalez E, Zayas C, Balboa J, Cuello M, Cabrera O, Lastre M, Schijns VE. Human prophylactic vaccine adjuvants and their determinant role in new vaccine formulations. Brazilian Journal of Medical and Biological Research. 2012; 45: 681-692.

11. Nascimento IP, Leite LC. Recombinant vaccines and the development of new vaccine strategies. Brazilian Journal of Medical and Biological Research. 2012; 45:1102-1111.

12. Buatois V, Baillet M, Becart S, Mooney N, Leserman L, Machy P. MHC class II-peptide complexes in dendritic cell lipid microdomainsinitiate the CD4 Th1 phenotype. The Journal of Immunology. 2003; 171: 5812 5819.

13. Chlibek R, Bayas JM, Collins H, de la Pinta ML, Ledent E, Mols JF, Heineman TC. Safety and immunogenicity of an AS01-adjuvanted varicella-zoster virus subunit candidate vaccine against herpes zoster in adults $\geq 50$ years of age. The Journal of Infectious Diseases. 2013; 208(12): 1953-1961.

14. Stober D, Trobonjaca Z, Reimann J, Schirmbeck R. Dendritic cells pulsed with exogenous hepatitis B surface antigen particles efficiently present epitopes to MHC class I-restricted cytotoxic T cells. European Journal of Immunology. 2002; 32: 1099-1108.

15. Aljanabi SM, Martinez I. Universal and rapid salt-extraction of high quality genomic DNA for PCR based techniques. Nucleic Acids Research. 1997; 25: 4692-4693.

16. Li X, Sui X, Zhang Y, Sun Y, Zhao Y, Zhai Y, Wang Q. An improvised calcium chloride method preparation and transformation of competent cells. African Journal of Biotechnology. 2010; 9:8549-8554.
17. Bringans S, Eriksen S, Kendrick T, Gopalakrishnakone P, Livk A, Lock $\mathrm{R}$, Lipscombe R. Proteomic analyses of the venom of Heterometrus longimanus (Asian black scorpion). Proteomics. 2008; 8: 1084-1096.

18. Wessel D, Flugge UI. A method for the quantitative recovery of protein in dilute solution in the presence of detergent and lipids. Analytical Biochemistry. 1984; 138: 141-143.

19. Saylor C, Dadachova E, Casadevall A. Monoclonal antibody-based therapies for microbial diseases. Vaccine. 2009; 27(6): G38-G46.

20. Tkaczyk C, Hua L, Varkey R, Shi Y, Dettinger L, Woods R, Barnes A, MacGill RS, Wilson S, Chowdhury P, Stover CK, Sellman BR. Identification of anti-alpha toxin monoclonal antibodies that reduce the severity of Staphylococcus aureus dermonecrosis and exhibit a correlation between affinity and potency. Clinical and Vaccine Immunology. 2012; 19:377-385

21. Fynan EF, Webster RG, Fuller DH, Haynes JR, Santoro JC, Robinson HL. DNA vaccines: prospective immunizations by parenteral, mucosal and gene-gun inoculations. Proceedings of the National Academy of Sciences USA. 1993; 90: 11478-11482.

22. Cripps AW, Dunkley ML, Clancy RL. Mucosal and systemic immunizations with killed Pseudomonas aeruginosa protect against acute respiratory infection in rats. Infection and Immunity. 1994; 62: 14271436

23. Lee N, Ahn B, Kim YG, Kim H, Park WJ. Conformation-dependent antibody response to Pseudomonas aeruginosa outer membrane protein induced by immunization in humans. FEMS Immunology and Medical Microbiology. 2000; 27: 79-85.

24. Robinson HL, Ginsberg HS, Davis HL, Johnston, SA, Liu MA. The scientific future of DNA for immunization. American Academy of Microbiology critical issues colloquia. Washington, DC; 1997.

25. Gilleland HE, Gilleland LB, Staczek J, Harty RN, Garcia-Sastre A, Palase P, Brennan FR, Hamilton WD, Bendahmane M, Beachy RN. Chimeric animal and plant viruses expressing epitopes of outer membrane protein $\mathrm{F}$ as a combined vaccine against Pseudomonas aeruginosa lung infection. FEMS Immunology and Medical Microbiology. 2000; 27:291-297.

26. Anderson R, Gao XM, Papakonstantinopoulou A, Roberts M, Dougan G. Immune response in mice following immunization with DNA encoding fragment C of tetanus toxin. Infection and Immunity. 1996; 64: 3168 3173

27. Barry MA, Lai WC, Johnston SA. Protection against Mycoplasma infection using expression-library immunization. Nature. 1995; 377: 632635

28. Paul W, Reena V, Bonnell JC, DiGiandomenico A, Camara M, Cook K, Peng L, Zha J, Chowdury, Sellman B, Stover CK. A novel anti-PcrV antibody providing enhanced protection against Pseudomonas aeruginosa in multiple animal infection models. Antimicrobial Agents and Chemotherapy. 2014; 58:4384-4391.

29. Brian M, Price, Darrell R, Galloway, Harry E, Gilleland. Protection against Pseudomonas aeruginosa Chronic Lung Infection in Mice by Genetic Immunization against Outer Membrane Protein $\mathrm{F}(\mathrm{OprF})$ of $P$. aeruginosa. Infection and Immunity. 2001; 69 (5): 3510-3515.

30. Mingzi J, Jing Y, Ganzhu F. Protective effect of DNA vaccine encoding Pseudomonas exotoxin against acute pulmonary Pseudomonas aeruginosa infection. PLOS Pathogen. 2014; 9(5): e96609.

31. Fox CW, Campbell GD, Anderson MM, Zavecz JH, Gilleland LB, Gilleland HE. Preservation of pulmonary function by an outer membrane protein $\mathrm{F}$ vaccine: a study in rats with chronic pulmonary infection caused by Pseudomonas aeruginosa. Chest. 1994; 105: 1545-1550.

\section{How to cite this article:}

Bhuiyan SA, Sultana H, Opook, F Rodrigues KF. Characterization of the pscC (Type III secretion) gene of Pseudomonas aeruginosa (PA01) and assessment of immunogenicity of pscC protein in rats. J App Biol Biotech. 2017; 5 (01): 035-041. DOI: 10.7324/JABB.2017.50106 